\title{
A POSSIBLE ROLE OF ELEVATED BREAST MILK LACTOFERRIN AND THE CYTOKINE IL-17 LEVELS IN PREDICTING EARLY ALLERGY IN INFANTS: A PILOT STUDY
}

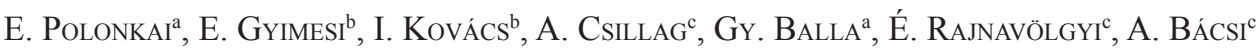 \\ and S. SIPKA ${ }^{\mathrm{b} *}$ \\ aDepartment of Pediatrics, University of Debrecen, H-4032 Debrecen, Nagyerdei körút 98. Hungary \\ ${ }^{\mathrm{b}}$ Division of Clinical Immunology, University of Debrecen, H-4032 Debrecen, Nagyerdei körút 98 . Hungary \\ 'Department of Immunology, University of Debrecen, H-4032 Debrecen, Nagyerdei körút 98. Hungary.
}

(Received: 1 April 2014; accepted: 30 July 2014)

\begin{abstract}
In this study, we examined the relationship between levels of lactoferrin (LF) and IL-17 in human serum and breast milk and the development of allergy in children. LF and IL-17 levels were determined by ELISA in healthy ( $\mathrm{n}=19)$ and allergic mothers $(\mathrm{n}=21)$ on the $5^{\text {th }}$ day after delivery. Two years later, information on breastfeeding and allergic outcomes was collected by questionnaires from parents of both groups and district child care nurses. Significantly higher concentrations of LF were found in the breast milk of allergic mothers compared to the healthy controls. At 2 years of age, only those three infants became allergic from the atopic group in whose starting breast milk samples a very high LF level (306 $\mu \mathrm{g} \mathrm{mg}^{-1}$ protein) or simultaneously elevated concentrations of LF and IL-17 were measured. These findings indicate that the very early measurement of LF and IL-17 levels in the breast milk of allergic mothers may help to predict the allergy development in their infants.
\end{abstract}

Keywords: allergy, atopy, breast milk, IL-17, lactoferrin, pollen allergy

There is a growing body of epidemiologic evidence supporting that maternal history of asthma predisposes offspring to atopic disorders more than paternal asthma (LiTONJUA et al., 1998; Bottcher \& Jenmalm, 2002; KurukulaAratchy et al., 2006). These observations can be explained by the fact that beside genetic factors originated from both parents, other maternal factors may play significant role in the transmission of allergy susceptibility; however, these factors have not been fully elucidated (Lim et al., 2010). For example, this maternal effect may be based on the fact that mitochondria are inherited exclusively through maternal line, suggesting the contribution of mitochondrial genetic background to the pathogenesis of asthma. Indeed, a strong association was demonstrated between a common mitochondrial haplogroup and total serum IgE levels (RABY et al., 2007), and between the same mitochondrial haplogroup and the severity of allergic disease (ZIFA et al., 2012). On the other hand, while breast-feeding provides population-level protection from infections and atopy in infancy and early childhood (WILLS-KARP et al., 2004), it might also pose an increased risk of atopic asthma among children with asthmatic mothers (BOTTCHER \& JENMALM, 2002). It is still unknown, which components of breast milk might be responsible for the various effects of breast milk in allergic and non-allergic mothers. Immunoglobulins, cytokines (e.g. IL-4, TGF- $\beta_{1}$ ), chemokines (e.g. IL-8, RANTES), fatty acids, and leucocytes have all been suggested as potential candidates (JARVINEN \& SuOMALAINEN, 2001).

\footnotetext{
* To whom correspondence should be addressed. Phone/fax: +36-52-255-218; e-mail: sipka@iiibel.dote.hu
} 
Recent studies have reported that serum IL-17 (CIPRANDI et al., 2008) and lactoferrin (LF) (CHOI et al., 2010) levels are strongly associated with the phenotypes of allergic rhinitis. Therefore, in this study, we investigated the associations between the serum and breast milk levels of these mediators and the development of allergy in infants.

\section{Materials and methods}

The study population comprised 19 healthy and 21 allergic mothers with verified and confirmed pollen allergy forming two groups matched in age, type of delivery, duration of breast feeding, and number of antibiotic treatments. The study was conducted in a pollen free season, when all patients were free of any allergic symptoms. Informed written consent was obtained from the mothers before the study. The study was approved by the Regional and Institutional Ethics Committee of the University of Debrecen.

Breast milk was collected from each mother by manual expression into sterile polypropylene containers on the $5^{\text {th }}$ day after delivery at the Department of Gynecology at the University of Debrecen. To reduce potential diurnal variability in cytokine measurements, mothers were instructed to collect the milk samples in the early morning during the first breastfeeding. Infants were allowed to suckle the nipple for a few minutes, and then a breast milk sample (3-6 ml) was taken and the feeding was continued. The milk samples were centrifuged in two consecutive steps to remove cells (2000 r.p.m., $10 \mathrm{~min}$, room temperature) and fat (6000 r.p.m., $10 \mathrm{~min}, 4{ }^{\circ} \mathrm{C}$ ) (Rudloff et al., 1999). Cell- and fat-free milk samples were transferred to the freezer and kept at $-70{ }^{\circ} \mathrm{C}$ until analysis. On the same day, blood samples from mothers were drawn by venous puncture, were centrifuged. The sera were frozen and stored at $-70{ }^{\circ} \mathrm{C}$.

Two years later, information on breastfeeding, allergic outcomes, medication, and hospitalization was collected by questionnaires from parents and district child care nurses. The study groups' information is summarized in Table 1.

LF (Calbiochem, Darmstadt, Germany) and IL-17 (R\&D Systems, Minneapolis, MN, USA) levels in human serum and breast milk were determined by using ELISA according to the manufacturer's instructions. Total protein concentration in breast milk samples was measured using COBAS Mira Plus (Roche Diagnostics, Basel, Switzerland) automated chemistry analyser.

For comparison of variables between two groups, the Mann-Whitney U-test or Student's $t$-test was used. Data analysis was performed with SPSS version 12.0 for Windows (SPSS Inc. Chicago, IL, USA). Differences were considered to be statistically significant at $\mathrm{P}<0.05$. 
Table 1. Characteristics of the patient population

\begin{tabular}{|c|c|c|c|}
\hline Characteristics & $\begin{array}{l}\text { Allergic mothers } \\
\qquad(\mathrm{n}=21)\end{array}$ & $\begin{array}{l}\text { Non-allergic mothers } \\
\qquad(\mathrm{n}=19)\end{array}$ & $\mathrm{P}$ \\
\hline $\begin{array}{l}\text { Age of mother at delivery } \\
\text { Years, mean (SD) }\end{array}$ & $29.8(4.2)$ & $28.9(3.9)$ & 0.511 \\
\hline $\begin{array}{l}\text { Vaginal delivery / cesarean section } \\
\text { No. / no. }\end{array}$ & $21 / 0$ & $19 / 0$ & - \\
\hline \multicolumn{4}{|l|}{ Season of breast milk collection } \\
\hline October - December, no. (\%) & $7(33.3)$ & $19(100)$ & - \\
\hline January - April, no. (\%) & $14(66.7)$ & $0(0)$ & - \\
\hline $\begin{array}{l}\text { Duration of exclusive breastfeeding } \\
\text { Weeks, mean (range) }\end{array}$ & 26.8 & 29.3 & 0.771 \\
\hline $\begin{array}{l}\text { Antibiotic treatment during infancy } \\
\text { No. }(\%)\end{array}$ & $5(23.8)$ & $6(31.6)$ & 0.587 \\
\hline \multicolumn{4}{|l|}{$\begin{array}{l}\text { Allergic clinical symptoms during } \\
\text { infancy } \\
\text { (until } 2 \text { years of age) }\end{array}$} \\
\hline Allergic bronchitis, no. & 1 & - & \\
\hline Allergic dermatitis, no. & 2 & - & \\
\hline $\begin{array}{l}\text { Breast milk total protein concentration } \\
\text { Mean (range), } \mathrm{mg} \mathrm{ml}^{-1}\end{array}$ & $24(12.8-68.2)$ & $24.5(13.8-71)$ & 0.911 \\
\hline
\end{tabular}

Inclusion criteria for this study were (I) pregnancy and giving birth without any complications, (II) availability of completed questionnaire about allergic conditions, and (III) availability of blood and breast milk samples. Maternal atopy: self-reported seasonal rhinoconjunctivitis or pollen (Ambrosia artemisiifolia, Plantago lanceolata, Artemisia vulgaris, Solidago gigantea) allergy diagnosed by doctor/specialist.

\section{Results and discussion}

There was a great difference in the detection of LF and IL-17 in the sera and breast milk samples. Whereas LF occurred in a measurable concentration in each serum and milk sample (in 100\%), IL-17 was detectable only in a much less rate in both types of samples (in a range of $5-19 \%)$. These data are shown in Table 2. 
Table 2. Detection of LF and IL-17 in serum and breast milk of allergic and non-allergic mothers (presented as percentage of number of samples)

\begin{tabular}{lcccccc}
\hline \multirow{2}{*}{ Parameter } & Cut-off $\left(\mathrm{pg} \mathrm{m}^{-1}\right)$ & \multicolumn{2}{c}{ Serum } & & \multicolumn{2}{c}{ Breast milk } \\
\cline { 3 - 4 } \cline { 5 - 6 } & & Allergic $\%$ & Non-allergic\% & & Allergic\% $\%$ & Non-allergic\% \\
\hline LF & 1000 & 100 & 100 & 100 & 100 \\
IL-17 & 4 & 10 & 5 & 19 & 11 \\
\hline
\end{tabular}

The cut-off values were provided by the manufacturer or determined by adding three standard deviations to the mean optical density value of twenty zero standard replicates and calculating the corresponding concentration.

Although the levels of LF were markedly higher in the sera of allergic mothers as compared to those of non-allergic mothers, the differences were not statistically significant $(\mathrm{P}=0.163)$. However, the LF concentrations were significantly higher $(\mathrm{P}<0.05)$ in the breast milk (either expressed in $\mathrm{mg} \mathrm{ml}^{-1}$ or $\mu \mathrm{g} \mathrm{mg}^{-1}$ protein units) of allergic mothers. The amount of IL-17 was higher both in the serum $(\mathrm{P}=0.594)$ and breast milk $(\mathrm{P}=0.383)$ of allergic mothers, but these differences also were found statistically not significant (Table 3 ).

Table 3. LF and IL-17 levels in the serum and breast milk of allergic $(\mathrm{n}=21)$ and non-allergic mothers $(\mathrm{n}=19)$

\begin{tabular}{|c|c|c|c|c|c|c|c|}
\hline & \multicolumn{3}{|c|}{ Allergic mothers } & \multicolumn{3}{|c|}{ Non-allergic mothers } & \multirow[t]{2}{*}{$\mathrm{P}$} \\
\hline & Mean & Median & Range & Mean & Median & Range & \\
\hline $\begin{array}{l}\text { LF in the serum } \\
\left(\mathrm{ng} \mathrm{ml}^{-1}\right)\end{array}$ & - & 569.2 & $\begin{array}{l}253.2- \\
2232.8\end{array}$ & - & 380 & $\begin{array}{c}126.8- \\
346.8\end{array}$ & 0.163 \\
\hline $\begin{array}{l}\text { LF in the milk } \\
\left(\mathrm{mg} \mathrm{ml}^{-1}\right)\end{array}$ & $3.36^{*}$ & - & $2.02-4.31$ & $2.88^{*}$ & - & $1.32-4.88$ & $0.037 *$ \\
\hline $\begin{array}{l}\text { LF in the milk } \\
\text { ( } \mu \mathrm{g} / \mathrm{mg} \text { protein) }\end{array}$ & - & $171.75^{*}$ & $55.5-306$ & - & $136.75^{*}$ & 49-191.5 & $0.032 *$ \\
\hline $\begin{array}{l}\text { IL-17 in the serum } \\
\left(\mathrm{pg} \mathrm{ml}^{-1}\right)\end{array}$ & - & $<4$ & $<4-27.56$ & - & $<4$ & $<4-4.88$ & 0.594 \\
\hline $\begin{array}{l}\text { IL-17 in the milk } \\
\left(\mathrm{pg} \mathrm{ml}^{-1}\right)\end{array}$ & - & $<4$ & $<4-47.94$ & - & $<4$ & $<4-14.45$ & 0.383 \\
\hline $\begin{array}{l}\text { IL-17 in the milk } \\
\text { (pg } \mathrm{mg}^{-1} \text { protein) }\end{array}$ & - & 0.023 & $0.01-2.77$ & - & 0.022 & $0.01-1.05$ & 0.839 \\
\hline
\end{tabular}

*: Significantly different at $\mathrm{P}<0.05$ level

At 2 years of age, none of the infants of non-atopic mothers showed allergic symptoms. On the other hand, the cumulative incidence of allergic disorders in the group of infants from atopic mothers was $14 \%(3 / 21)$. Table 1 demonstrates all LF and IL-17 data of the atopic mothers. When the associations of breast milk levels of LF and IL-17 with the development of allergic symptoms were further analysed, we found that each of the three atopic mothers 
with allergic infants had higher level of LF in their breast milk than the mean of the allergic group ( $3.36 \mathrm{mg} \mathrm{ml}^{-1}$ versus $3.92,4.17$, and $306 \mathrm{mg} \mathrm{ml}^{-1}$ ). It was of a special note that in one of the atopic mothers, the concentration of breast milk reached the extra high level of 306 $\mathrm{mg} \mathrm{ml}^{-1}$ (without an increase in IL-17). However, the simultaneously elevated LF and IL-17 levels could be detected exclusively in the milk of the two other atopic mothers.

Epidemiologic data suggest that rather the maternal than the paternal history of asthma confers a significant risk for the development of allergy in infants (Lim et al., 2010). As an earlier study demonstrated lower serum LF levels in patients with allergy (Сног et al., 2010), we expected in our study that the levels of LF would be lower in the breast milk of allergic mothers than in the healthy subjects. To our surprise, we have found that levels of LF were significantly elevated in the breast milk of allergic mothers. Our results can be explained by the earlier systemic activation of peripheral blood phagocytes (neutrophils) still in the acute phase of seasonal allergic rhinoconjunctivitis prior/during pregnancy. Indeed, it was already described that a great amount of various inflammatory mediators could be released during the active period of an allergic inflammation even from a small area of the body (like rhinoconjunctivitis) causing a generalized and long-lasting activation of neutrophils (KAlLENBACH et al., 1992; SzABó et al., 2000). LF released by activated neutrophils may mediate numerous compensatory effects to inhibit allergic inflammations, decreasing mast cell degranulation, tryptase activity, eosinophils' migration, and promoting the Th1-type immune responses (ELrod et al., 1997; He et al. 2003; DE LA Rosa et al., 2008; Bournazou et al., 2010). Our other finding, that IL-17 was more frequently detectable and its levels were higher (although not significantly) both in the serum and breast milk of allergic mothers, supports the previous observation that some patients with pollen-induced allergic rhinitis may have high serum IL-17 levels outside of the pollen season (CIPRANDI et al., 2008). However, in our study, only those infants became allergic, whose mothers had a very high LF level (306 $\mu \mathrm{g} \mathrm{mg}^{-1}$ proteins) or simultaneously elevated LF or IL-17 concentrations in the breast milk on the $5^{\text {th }}$ day after delivery. Thus, these markers can be regarded as some kinds of predictive factors for allergy development in infants. In the three allergic mothers, the ability for the increased production of LF and IL-17 can be such a sensitive marker of a stronger atopic genetic background that has not only been effectively inherited by their children, thus owning a positive predictive value for early allergy, but it also separates them from those atopic mothers, who are lacking this capability. These observations, however, need further confirmation in a larger study population in the future.

\section{Conclusions}

The early prediction of allergy in the newborns is one of the most important wish for atopic mothers and task for the paediatricians. This pilot study suggests that the demonstration of high levels of lactoferrin and/or IL-17 in the breast milk of mothers can be a useful approach.

This work was supported by the Hungarian Medical Research Council (ETT150/2006 to S.S.), the Hungarian Scientific Research Fund (K-75883 to G.B. and K-109595 to A.B.), and the TÁMOP-4.2.2.A-11/1/KONV-20120045 (G.B.). The project is co-financed by the European Union and the European Social Fund. A.B. was also supported by the Janos Bolyai Fellowship from the Hungarian Academy of Sciences. G.B. was also supported by the Hungarian Academy of Sciences and the University of Debrecen (Vascular Biology, Thrombosis-haemostasis Research Group, 11003/2012-2016). 


\section{References}

Bottcher, M.F. \& Jenmalm, M.C. (2002): Breastfeeding and the development of atopic disease during childhood. Clin. Exp. Allergy, 32, 59-161.

Bournazou, I., Mackenzie, K.J., Duffin, R., Rossi, A.G. \& Gregory, C.D. (2010): Inhibition of eosinophil migration by lactoferrin. Immunol. Cell. Biol., 88, 220-223.

Choi, G.S., Shin, S.Y., Kim, J.H., Lee, H.Y., Palikhe, N.S., Ye, Y.M., Kim, S.H. \& Park, H.S. (2010): Serum lactoferrin level as a serologic biomarker for allergic rhinitis. Clin. Exp. Allergy, 40, 403-410.

Ciprandi, G., Fenoglio, D., De Amici, M., Quaglini, S., Negrini, S. \& Filaci, G. (2008): Serum IL-17 levels in patients with allergic rhinitis. J. Allergy Clin. Immun., 122, 650-652.

de la Rosa, G., Yang, D., Tewary, P., Varadhachary, A. \& Oppenheim, J.J. (2008): Lactoferrin acts as an alarmin to promote the recruitment and activation of APCs and antigen-specific immune responses. J. Immunol. 180, 6868-6876.

Elrod, K.C., Moore, W.R., Abraham, W.M. \& Tanaka, R.D. (1997): Lactoferrin, a potent tryptase inhibitor, abolishes late-phase airway responses in allergic sheep. Am. J. Resp. Crit. Care, 156, 375-381.

He, S., Mceuen, A.R., Blewett, S.A., Li, P., Buckley, M.G., Leufkens, P. \& Walls, A.F. (2003): The inhibition of mast cell activation by neutrophil lactoferrin: uptake by mast cells and interaction with tryptase, chymase and cathepsin G. Biochem Pharmacol., 65, 1007-1015.

Jarvinen, K.M. \& Suomalainen, H. (2001): Development of cow's milk allergy in breast-fed infants. Clin. Exp. Allergy, 31, 978-987.

Kallenbach, J., Baynes, R., Fine, B., Dajee, D. \& Bezwoda, W. (1992): Persistent neutrophil activation in mild asthma. J. Allergy Clin. Immun., 90, 272-274.

Kurukulaaratchy, R.J., Matthews, S. \& Arshad, S.H. (2006): Relationship between childhood atopy and wheeze: what mediates wheezing in atopic phenotypes? Ann. Allerg. Asthma Im., 97, 84-91.

Lim, R.H., KoBziK, L. \& DAHL, M. (2010): Risk for asthma in offspring of asthmatic mothers versus fathers: a metaanalysis. PLoS One , 5, 10134.

Litonjua, A.A., Carey, V.J., Burge, H.A., Weiss, S.T. \& Gold, D.R. (1998): Parental history and the risk for childhood asthma. Does mother confer more risk than father? Am. J. Resp. Crit. Care, 158, 176-181.

Raby, B.A., Klanderman, B., Murphy, A., Mazza, S., Camargo, C.A., Jr.., Silverman, E.K. \& Weiss, S.T. (2007): A common mitochondrial haplogroup is associated with elevated total serum IgE levels. J. Allergy Clin. Immun., 120, 351-358.

Rudloff, S., Niehues, T., Rutsch, M., Kunz, C. \& Schroten, H. (1999): Inflammation markers and cytokines in breast milk of atopic and nonatopic women. Allergy, 54, 206-211.

Szabó, Z., Szilasi, M., Brugos, L., Szanto, S., Kovacs, I., Szeles, M., Lakos, G., Antal-Szalmas, P., Edes, I. \& SIPKA, S. (2000): Differences in the changes of allergen-specific IgE serum levels and the chemiluminescence of peripheral blood phagocytes in patients with allergic rhinoconjunctivitis during the ragweed season. Immunol. Lett., 74, 201-205.

Wills-Karp, M., Brandt, D. \& Morrow, A.L. (2004): Understanding the origin of asthma and its relationship to breastfeeding. Adv. Exp. Med. Biol., 554, 171-191.

Zifa, E., Danill, Z., Skoumi, E., Stavrou, M., Papadimitriou, K., Terzenidou, M., Kostikas, K., Bagiatis, V., Gourgoulianis, K.I. \& Mamuris, Z. (2012): Mitochondrial genetic background plays a role in increasing risk to asthma. Mol. Biol. Rep., 39, 4697-4708. 